\title{
Adhesion to and invasion of pulmonary epithelial cells by the F15/LAM4/KZN and Beijing strains of Mycobacterium tuberculosis
}

Correspondence

A. Willem Sturm

sturm@ukzn.ac.za

Received 19 September 2009

Accepted 25 January 2010

\author{
Olubisi T. Ashiru, Manormoney Pillay and A. Willem Sturm
} Medical Microbiology Research Laboratories, Nelson R. Mandela School of Medicine, University of
KwaZulu-Natal, South Africa

\begin{abstract}
Globally, specific genotypes of Mycobacterium tuberculosis have been shown to dominate in patients, suggesting that these are more successful pathogens. One such genotype, the F15/LAM4/KZN (KZN) family of M. tuberculosis, has predominated in KwaZulu-Natal, South Africa, since the early 1990s. This strain recently evolved from multidrug-resistant to extensively drug-resistant (XDR). The ability of $M$. tuberculosis strains belonging to the Beijing family, the KZN family, strains with unique DNA fingerprint patterns and laboratory strains (H37Rv and H37Ra) to adhere to and invade a human alveolar (A549) and a human bronchial (BBM) epithelial cell line was investigated. All strains displayed greater adhesion to and invasion of A549 cells as compared to BBM cells. The Beijing and KZN strains combined showed greater adhesion (28\%) than the unique strains $(5 \%)(P<0.05)$. The XDR variant of $\mathrm{KZN}$ invaded $\mathrm{A} 549$ cells more effectively than the other isolates. These results suggest that the successful spread of the Beijing and $\mathrm{KZN}$ strains might be related to their interaction with alveolar epithelium.
\end{abstract}

\section{INTRODUCTION}

South Africa is fifth among the 22 high tuberculosis (TB) burden countries, having incidence and mortality rates of 948 and 230, respectively, per 100000 population in 2007 (WHO, 2009). This may be attributed to the increasing rates of HIV co-infection (CDC, 2008). Strain-specific molecular markers (Van Embden et al., 1993) have identified TB patients with isolates of M. tuberculosis that share highly similar DNA fingerprint patterns (Van Soolingen et al., 1999; Hawkey et al., 2003) (Table 1). These dominate in patients in different geographical regions, suggesting that shared fingerprints may be a marker of increased transmission efficacy and might indicate recent transmission (Weis et al., 2002), while infection with unique DNA fingerprint patterns suggests $\mathrm{TB}$ reactivation.

In KwaZulu-Natal, two families of strains dominate: Beijing and F15/LAM4/KZN (KZN). The latter has evolved since the early 1990s into a family of closely related strains accompanied by its progression from a multidrug-resistant to an extensively drug-resistant (XDR) strain (Pillay \& Sturm, 2007). The rapid spread of this strain with concomitant high mortality among HIV-infected patients

Abbreviations: TB, tuberculosis; XDR, extensively drug-resistant.

Supplementary information on adhesion to and invasion of cells by individual M. tuberculosis isolates is available with the online version of this paper. in the Tugela Ferry region of KwaZulu-Natal province (Gandhi et al., 2006) is suggestive of its increased virulence.

Pulmonary epithelial cells may be the first barrier that the organism faces (Pessolani et al., 2003), as there is a predominance of epithelial cells in the lung (Crandall \& Kim, 1991). M. tuberculosis has been shown to adhere to, invade, as well as replicate within pulmonary epithelial cells (Bermudez \& Goodman, 1996; Bermudez et al., 2002; HallStoodley et al., 2006). We hypothesized that the effective transmission of the Beijing and KZN strain families results from a greater capacity than strains with unique DNA fingerprints to adhere to and invade the pulmonary epithelial cells.

Table 1. Global strain families of Mycobacterium tuberculosis

\begin{tabular}{|c|c|}
\hline Strain/family & Reference \\
\hline CAS & Sreevatsan et al. (1997); Al-Hajoj et al. (2007) \\
\hline EAI & Sreevatsan et al. (1997); Al-Hajoj et al. (2007) \\
\hline MANU family & Sreevatsan et al. (1997); Al-Hajoj et al. (2007) \\
\hline CDC 1551 & Valway et al. (1998) \\
\hline T family & Sola et al. (2001); Nouvel et al. (2006) \\
\hline Beijing family & Glynn et al. (2002) \\
\hline F28 & Streicher et al. (2004) \\
\hline Haarlem family & Mardassi et al. (2005) \\
\hline LAM3/F11 & Nicol et al. (2005) \\
\hline F15/LAM4/KZN & Pillay \& Sturm (2007) \\
\hline U family & Dou et al. (2008) \\
\hline
\end{tabular}




\section{METHODS}

Strains and growth conditions. Three isolates of the Beijing family, six of the KZN family of strains, including three XDR, and six isolates with unique DNA fingerprints were obtained from the culture collection of the Medical Microbiology Research Laboratories, University of KwaZulu-Natal, Durban. Laboratory strains of $M$. tuberculosis H37Rv (ATCC 27294) and H37Ra (ATCC 25177) were also included. The isolates were cultured under aerobic conditions on Middlebrook 7H11 complete agar media (Difco) containing $10 \%$ oleic acid, albumin, dextrose, catalase (OADC) and $0.05 \%$ Tween 80 (Sigma) at $37{ }^{\circ} \mathrm{C}$ for approximately 3 weeks.

Preparation of inocula. Cultures were harvested into $14 \mathrm{ml}$ PBS containing $0.05 \%$ Tween 80 and glass beads ( $3 \mathrm{~mm}$ diameter). The suspensions were vortexed for $5 \mathrm{~min}$, after which larger clumps were allowed to settle for $15 \mathrm{~min}$. To obtain a single cell suspension, the top $6 \mathrm{ml}$ was aspirated 10 times through a 26-gauge needle (Stokes et al., 2004) and passed through a $5 \mu \mathrm{m}$ Millipore filter. Aliquots of a 10 -fold serial dilution of the mycobacterial suspension were plated on Middlebrook 7H11 agar in triplicate to determine the number of c.f.u. per 100 epithelial cells used in the adhesion experiments.

Epithelial cell lines. The human type II alveolar epithelial cell line A549 (ATCC CCL 185) and a human bronchial epithelial cell line, BBM (CRL 9482 - a derivative of BEAS-2B), were used in the adhesion and invasion assays. A549 cells were maintained in Eagle's Minimum Essential Medium (Biowhittaker-Lonza) containing Earle's Balanced Salt Solution and $25 \mathrm{mM}$ HEPES supplemented with $10 \%$ heat-inactivated fetal bovine serum (Gibco, Invitrogen) and $2 \mathrm{mM}$ L-glutamine. BBM cells were maintained in Bronchial Epithelial Basal Medium (Lonza) supplemented with Bronchial Epithelial Growth Medium (Lonza). Cells were maintained following standard tissue culture practice (Bermudez \& Goodman, 1996). After trypsinization, viable cells were seeded onto glass coverslips (12 mm diameter) in a 24-well tissue culture plate at a concentration of $10^{5}$ cells $\mathrm{ml}^{-1}$ and incubated for $\pm 40 \mathrm{~h}$ at $37{ }^{\circ} \mathrm{C}$ in a $5 \% \mathrm{CO}_{2}$ atmosphere.

Adhesion assay. Cells were inoculated with the M. tuberculosis suspensions at an m.o.i. of 9-12 bacteria per epithelial cell and incubated at $37{ }^{\circ} \mathrm{C}$ in a $5 \% \mathrm{CO}_{2}$ atmosphere for $1 \mathrm{~h}$. Thereafter, the cells were washed and fixed with $95 \%$ ethanol. The coverslips were mounted on microscope slides using distyrene plasticizer xylene with the infected side facing upward. The slides were left overnight at room temperature and then stained by the Ziehl-Neelsen staining method. The acid-fast bacilli per 100 epithelial cells were counted using light microscopy and the percentage adhesion was calculated using the number of bacteria added per 100 cells as the denominator. A total of 300 epithelial cells were examined in each reported attachment assay. To ascertain that the bacilli do not attach to glass, coverslips without epithelial cells were also inoculated and incubated as described above.

Invasion assay. The method of Bermudez \& Goodman (1996) was used with minor modifications. After inoculation with M. tuberculosis suspension at an m.o.i. of 9-12 bacteria per epithelial cell, the cells were incubated at $37{ }^{\circ} \mathrm{C}$ in a $5 \% \mathrm{CO}_{2}$ atmosphere for $2 \mathrm{~h}$. Following this, the cells were incubated for $1 \mathrm{~h}$ at $37{ }^{\circ} \mathrm{C}$ in $5 \% \mathrm{CO}_{2}$ in the presence of amikacin $\left(100 \mu \mathrm{g} \mathrm{ml}^{-1}\right.$; Sigma $)$. Medium was removed and inoculated on Middlebrook 7H11 plates to confirm killing of extracellular organisms. The amikacin was removed by washing three times with PBS and the cells were lysed with $0.5 \mathrm{ml} 0.1 \%$ Triton X-100 in distilled water for $20 \mathrm{~min}$. The harvest was suspended in $0.5 \mathrm{ml}$ Middlebrook 7H9 broth and plated on Middlebrook 7H11 agar to determine the number of viable internalized organisms.

Statistical analysis. Microsoft Excel as well as Graphpad Instat software were used to determine whether there were significant differences in the adhesion and invasion abilities among the different strains. All comparisons were analysed initially by a one-way analysis of variance (ANOVA) and thereafter by Tukey-Kramer multiple comparisons test. All experiments were performed three times in triplicate for each isolate to assess intra-assay variability. Inter-assay variability was calculated to determine differences among the isolates belonging to the same strain or family.

Ethics approval. The study was approved by the Biomedical Research Ethics Committee of the University of KwaZulu-Natal (reference no. H039/06).

\section{RESULTS AND DISCUSSION}

Successful strains of $M$. tuberculosis such as the Beijing (Glynn et al., 2002) and KZN (Pillay \& Sturm, 2007) strains are capable of infecting large numbers of individuals in the same time period and therefore form genotype clusters. We hypothesized that the ability of the Beijing and KZN strains to adhere to and invade pulmonary epithelial cells exceeds that of strains with unique fingerprints, suggesting that they are more effective pathogens since they are better able to colonize the lung. All isolates adhered to and invaded the A549 cells much more effectively than the BBM cells.

\section{Adhesion of M. tuberculosis isolates to the A549 epithelial cell lines}

The Beijing and KZN strains combined showed a higher rate of adhesion to the A549 cell line when compared with the unique strains $(P<0.05)$ (Fig. 1a). Differences were observed in the rate of adhesion between the two families of strains. The Beijing family adhered more than the XDRKZN $(P<0.01)$ and KZN $(P<0.001)$ families (Table 2$)$. The Beijing $(P<0.001)$, XDR-KZN $(P<0.05), \mathrm{KZN}$ and unique isolates adhered more than the laboratory strains $\mathrm{H} 37 \mathrm{Rv}$ and $\mathrm{H} 37 \mathrm{Ra}$ (Table 2). Adhesion of virulent H37Rv was greater than that of the avirulent H37Ra $(P<0.05)$. No bacteria were observed on the glass coverslips without epithelial cells.

\section{Invasion of the A549 epithelial cells by $M$. tuberculosis isolates}

The Beijing and KZN strains together invaded the A549 cells more than the unique strains $(P<0.05)$ (Fig. 1b) Differences were observed among the groups of isolates in their ability to invade the A549 cells. The Beijing, XDRKZN and KZN strains had a higher rate of invasion of A549 cells when compared to the unique strains $(P<0.001)$ and the laboratory strains H37Rv $(P<0.001)$ and H37Ra $(P$ $<0.001$ ) (Table 3). The XDR-KZN strains had the highest invasion rate, followed by the Beijing strains and the KZN strains (Table 3). No growth was observed on the Middlebrook 7H11 agar plates that were inoculated with the discarded media, confirming that only internalized bacilli were reported.

The coefficient of variation $(\mathrm{CV})$ was low for the intraassay variability for all the isolates in both the adhesion and 
(a)

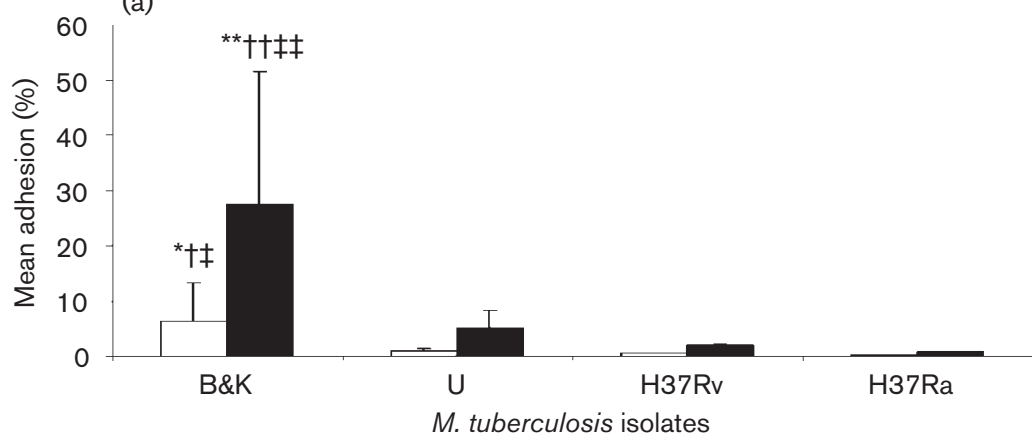

(b)

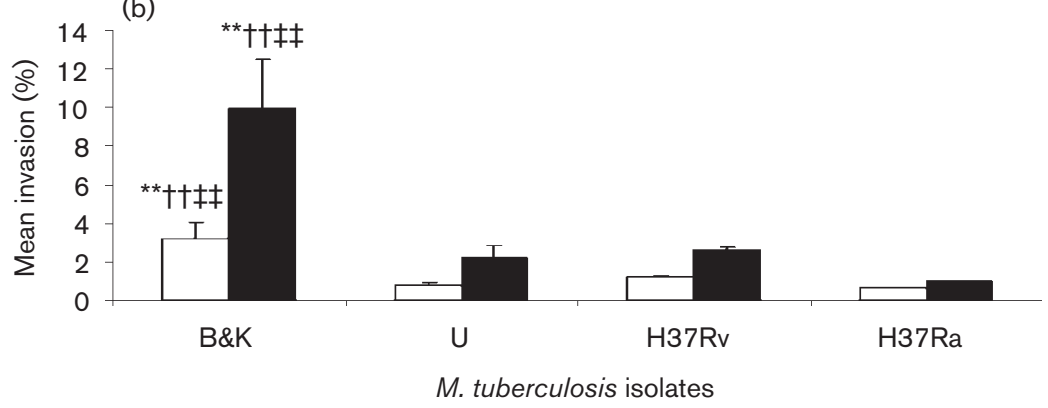

Fig. 1. Comparison of the capacity of strains of $M$. tuberculosis to adhere to and invade A549 (black bars) and BBM (white bars) epithelial cell lines. (a) Adhesion after $1 \mathrm{~h}$. (b) Invasion after $2 \mathrm{~h}$. B, Beijing isolates; $\mathrm{K}$, $\mathrm{F} 15 / \mathrm{LAM} 4 / \mathrm{KZN}$ isolates; $U$, isolates with unique DNA fingerprint patterns; H37Rv, virulent laboratory strain (ATCC 27294 positive control); H37Ra, avirulent laboratory strain (ATCC 25177 negative control). ${ }^{* *}, P<0.001,{ }^{*}, P<0.01$ when compared to H37Rv; ††, $P<0.001$, †, $P<0.01$ when compared to H37Ra; $\ddagger$, $P<0.001$, $\ddagger, P<0.01$ when compared to $U$.

Table 2. Adhesion to epithelial cells by M. tuberculosis strains

Epithelial cells were exposed to the inoculum for $1 \mathrm{~h}$ at $37{ }^{\circ} \mathrm{C}$. The results are means (\%) of three experiments performed in triplicate. CV, Coefficient of variation; SD, standard deviation.

\begin{tabular}{|c|c|c|c|c|c|c|}
\hline \multirow[t]{2}{*}{ M. tuberculosis strains } & \multicolumn{3}{|c|}{ A549 } & \multicolumn{3}{|c|}{ BBM } \\
\hline & Mean \pm SD & $P^{\star}$ & CV (\%) & Mean \pm SD & $P^{\star}$ & CV (\%) \\
\hline Beijing 1 & $62.44 \pm 0.98$ & $\dagger \ddagger$ & 1.18 & $7.11 \pm 0.08$ & $\dagger \neq$ & 1.17 \\
\hline 2 & $64.37 \pm 0.41$ & $\dagger \ddagger$ & 0.13 & $21.91 \pm 0.12$ & $\dagger$ & 0.55 \\
\hline 3 & $6.89 \pm 0.08$ & $\dagger+$ & 0.59 & $1.93 \pm 0.01$ & $\dagger \neq$ & 0.30 \\
\hline XDR-KZN 1 & $12.14 \pm 0.06$ & $\dagger \neq$ & 0.17 & $2.06 \pm 0.04$ & $\dagger \ddagger$ & 1.94 \\
\hline 2 & $14.06 \pm 0.06$ & $\dagger \neq$ & 0.25 & $3.77 \pm 0.11$ & $\dagger \neq$ & 2.98 \\
\hline 3 & $39.97 \pm 0.08$ & $\dagger \ddagger$ & 0.05 & $13.15 \pm 0.03$ & $\dagger \ddagger$ & 0.24 \\
\hline KZN 1 & $5.49 \pm 0.12$ & $\dagger \ddagger$ & 1.29 & $1.24 \pm 0.01$ & $\dagger \ddagger$ & 0.47 \\
\hline 2 & $7.17 \pm 0.03$ & $\dagger \ddagger$ & 0.16 & $2.35 \pm 0.01$ & $\dagger \ddagger$ & 0.25 \\
\hline 3 & $35.76 \pm 0.10$ & $\dagger \ddagger$ & 0.08 & $3.19 \pm 0.06$ & $\dagger \neq$ & 1.71 \\
\hline UNIQUE 1 & $4.64 \pm 0.05$ & $\dagger \neq$ & 0.33 & $0.74 \pm 0.01$ & $\ddagger$ & 1.57 \\
\hline 2 & $1.72 \pm 0.07$ & $\ddagger$ & 4.41 & $0.63 \pm 0.05$ & $\ddagger$ & 7.54 \\
\hline 3 & $10.31 \pm 0.31$ & $\dagger \ddagger$ & 3.42 & $1.63 \pm 0.01$ & $\dagger \ddagger$ & 0.61 \\
\hline 4 & $3.32 \pm 0.05$ & $\dagger \ddagger$ & 0.92 & $0.72 \pm 0.01$ & $\neq$ & 1.39 \\
\hline 5 & $3.25 \pm 0.05$ & $\dagger \neq$ & 0.47 & $0.71 \pm 0.04$ & $\ddagger$ & 5.84 \\
\hline 6 & $7.75 \pm 0.06$ & $\dagger \ddagger$ & 0.59 & $1.18 \pm 0.04$ & $\dagger \neq$ & 3.06 \\
\hline $\mathrm{H} 37 \mathrm{Rv}$ & $2.01 \pm 0.03$ & $\ddagger$ & 0.84 & $0.66 \pm 0.01$ & $\ddagger$ & 1.52 \\
\hline $\mathrm{H} 37 \mathrm{Ra}$ & $0.84 \pm 0.03$ & $\dagger$ & 3.81 & $0.26 \pm 0.01$ & $\dagger$ & 4.56 \\
\hline
\end{tabular}

${ }^{\star}$ Comparisons were performed initially by ANOVA and thereafter by Tukey-Kramer multiple comparisons test. $\dagger P<0.05$ compared with H37Rv.

$\ddagger P<0.05$ compared with H37Ra. 
invasion assays, while for the inter-assay variability the $\mathrm{CV}$ values of the three runs were close for each isolate (Supplementary Tables S1-S4 in JMM Online).

Although there is no consensus on the most appropriate method for enumerating attached bacilli and light microscopy may not be the optimal mechanism to quantify adhered bacteria, experiments were done three times in triplicate and the standard deviation was within an acceptable range (Supplementary Tables S1 and S2). The light microscopy could not differentiate between those bacteria that had invaded and those that adhered extracellularly. However, bacteria that invaded had first adhered to the epithelial cells.

The observation that adhesion and invasion of the avirulent H37Ra was minimal while adhesion and invasion of the virulent $\mathrm{H} 37 \mathrm{Rv}$ was similar to that of some of the unique isolates suggests that these assays do reflect mycobacterial virulence. Once inhaled bacilli reach the alveoli, they interact with the alveolar macrophages as well as the epithelial cells lining the alveoli (Reddy \& Hayworth, 2002). The infective dose is thought to be less than five bacilli (Small \& Fujiwara, 2001). While the role of the alveolar macrophages in the pathogenesis of TB has been extensively studied (Velasco-Velazquez et al., 2003; Aoki et al., 2004; Nguyen \& Pieters, 2005; Xue et al., 2007), less attention has been paid to the interaction of $M$. tuberculosis with epithelial cells (Reddy \& Hayworth, 2002; McDonough \& Kress, 1995). Since there are only a small number of alveolar macrophages (between 50 and 100) but large numbers of epithelial cells (28000 type I and 1400 type II) present in the alveolar space (Crandall \& Kim, 1991), the bacilli have a greater chance of encountering an epithelial cell than a macrophage (Bermudez et al., 2002). In addition, the chances of survival are much higher within epithelial cells than in the potential killing environment within the macrophage. Since invasion of non-professional phagocytes is usually microbe-initiated, the study of such interactions provides useful models to determine microbial determinants of infection (Glynn et al., 2002).

Our finding that all $17 \mathrm{M}$. tuberculosis isolates used in this study adhered to and invaded the alveolar cells (A549) more effectively than the bronchial cells (BBM) might be explained by the observation that bronchial epithelium resists infection by M. tuberculosis (Schluger \& Rom, 1998), and that the organism needs to be inhaled right into the alveoli for infection to occur (Small \& Fujiwara, 2001). Since bacterial adhesion to host cell surfaces is specific, our results suggest that $M$. tuberculosis possesses adhesins that interact with receptors present on the alveolar epithelial cell (Kohwiwattanagun et al., 2007).

The higher percentage of adhesion observed amongst the Beijing and KZN isolates as compared to the unique and

Table 3. Invasion of epithelial cells by M. tuberculosis strains

Epithelial cells were exposed to the various inocula for $2 \mathrm{~h}$ at $37^{\circ} \mathrm{C}$. The results are the mean (\%) of three experiments performed in triplicate. $\mathrm{CV}$, Coefficient of variation; SD, standard deviation.

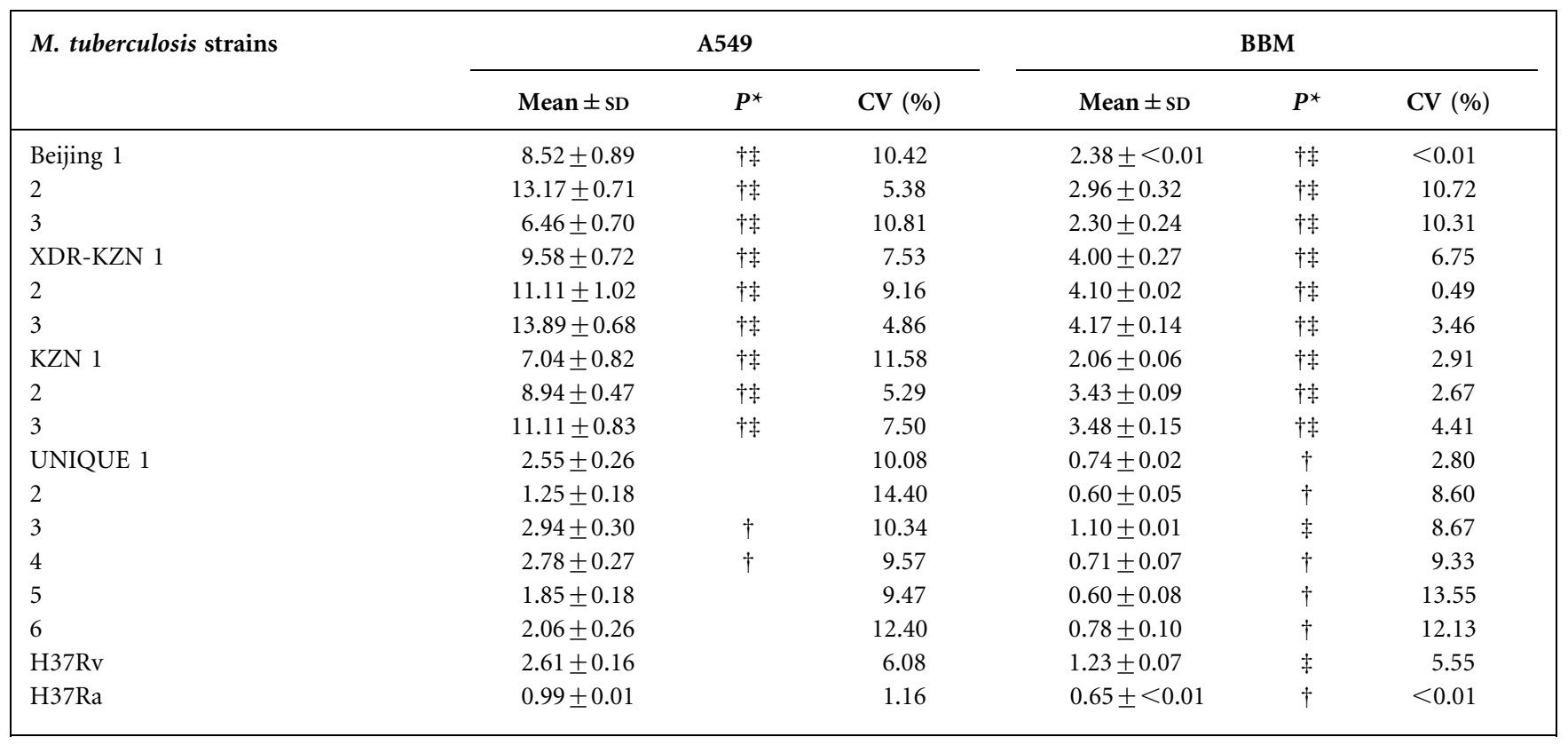

${ }^{*}$ Comparisons were performed initially by ANOVA and thereafter by Tukey-Kramer multiple comparisons test.

$\dagger P<0.05$ compared with H37Rv.

$\ddagger P<0.05$ compared with H37Ra. 
the type culture strains indicates that these strains have an increased capacity to colonize the alveoli. Two of the unique isolates with greater adhesion and invasion rates than some of the Beijing and KZN strains could have been involved in an undetected chain of transmission.

However, it is also possible that the lack of correlation between the relative adhesion and invasion levels and the variation between isolates result from multiple pathways of adhesion. These may include pili, recently described by Alteri et al. (2007), as well as different surface proteins (Reddy \& Hayworth, 2002) that use different cell surface receptors. In addition, invasion may be independent of adhesion (Garcia-Perez et al., 2003).

Our findings suggest that the higher adhesion to and invasion capacity of alveolar epithelial cells may contribute to the successful spread of the Beijing and KZN families of M. tuberculosis.

\section{REFERENCES}

Al-Hajoj, S. A. M., Zozio, T., Al-Rabiah, F., Mohammad, V., Al-Nasser, M., Sola, C. \& Rastogi, N. (2007). First insight into the population structure of Mycobacterium tuberculosis in Saudi Arabia. J Clin Microbiol 45, 24672473.

Alteri, C. J., Xicohtencatl-Cortes, J., Hess, S., Caballero-Olin, G., Giron, J. A. \& Friedman, R. L. (2007). Mycobacterium tuberculosis produces pili during human infection. Proc Natl Acad Sci U S A 104, 5145-5150.

Aoki, K., Matsumoto, S., Hirayama, Y., Wada, T., Ozeki, Y., Niki, M., Domenech, P., Umemori, K., Yamamoto, S. \& other authors (2004). Extracellular mycobacterial DNA-binding protein 1 participates in Mycobacterium-lung epithelial cell interaction through hyaluronic acid. J Biol Chem 279, 39798-39806.

Bermudez, L. E. \& Goodman, J. (1996). Mycobacterium tuberculosis invades and replicates within type II alveolar cells. Infect Immun 64, 1400-1406.

Bermudez, L. E., Sangari, F. J., Kolonoski, P., Petrofsky, M. \& Goodman, J. (2002). The efficiency of the translocation of Mycobacterium tuberculosis across a bilayer of epithelial and endothelial cells as model of the alveolar wall is a consequence of transport within mononuclear phagocytes and invasion of alveolar epithelial cells. Infect Immun 70, 140-146.

Crandall, E. D. \& Kim, K. J. (1991). Alveolar epithelial barrier properties. In The Lung: Scientific Foundations, pp. 273-287. Edited by R. J. Crystal \& J. B. West. New York: Raven Press.

CDC (2008). Extensively Drug-Resistant Tuberculosis (XDR TB) Update. Division of Tuberculosis Elimination (DTBE) and National Center for HIV/AIDS, Viral Hepatitis, STD and TB Prevention, Centers for Disease Control and Prevention. http://www.cdc.gov/tb/ $\mathrm{xdrtb} /$ update.htm

Dou, H. Y., Tseng, F. C., Lin, C. W., Chang, J. R., Sun, J. R., Tsai, W. S., Lee, S. Y. \& Lu, J. J. (2008). Molecular epidemiology and evolutionary genetics of Mycobacterium tuberculosis in Taipei. BMC Infect Dis 8, 170.

Gandhi, N. R., Moll, A., Sturm, A. W., Pawinski, R., Govender, T., Lalloo, U., Zeller, K., Andrews, J. \& Friedland, G. (2006). Extensively drug-resistant tuberculosis as a cause of death in patients co-infected with tuberculosis and HIV in a rural area of South Africa. Lancet 368, $1575-1580$.
Garcia-Perez, B. E., Mondragron-Flores, R. \& Luna-Herrera, J. (2003). Internalization of Mycobacterium tuberculosis by macropinocytosis in non-phagocytic cells. Microb Pathog 35, 49-55.

Glynn, J. R., Whiteley, J., Bifani, P. J., Kremer, K. \& Van Soolingen, D. (2002). Worldwide occurrence of Beijing/W strains of Mycobacterium tuberculosis: a systematic review. Emerg Infect Dis 8, 843-849.

Hall-Stoodley, L., Watts, G., Crowther, J. E., Balagopal, A., Torrelles, J. B., Robison-Cox, J., Bargatze, R. F., Harmsen, A. G., Crouch, E. C. \& Schlesinger, L. S. (2006). Mycobacterium tuberculosis binding to human surfactant proteins $\mathrm{A}$ and $\mathrm{D}$, fibronectin and small airway epithelial cells under shear conditions. Infect Immun 74, 3587-3596.

Hawkey, P. M., Smith, E. G., Evans, J. T., Monk, P., Bryan, G., Mohamed, H. H., Bardhan, M. \& Pugh, R. N. (2003). Mycobacterial interspersed repetitive unit typing of Mycobacterium tuberculosis compared to IS6110-based restriction fragment length polymorphism analysis for investigation of apparently clustered cases of tuberculosis. J Clin Microbiol 41, 3514-3520.

Kohwiwattanagun, J., Kawamura, I., Fujimura, T. \& Mitsuyama, M. (2007). Mycobacterial mammalian cell entry protein 1A (Mce 1A)mediated adherence enhances the chemokine production by A549 alveolar epithelial cells. Microbiol Immunol 51, 253-261.

Mardassi, H., Namouchi, A., Haltiti, R., Zarrouk, M., Mhenni, B., Karboul, A., Khabouchi, N., Van Pittius, N. C. G., Streicher, E. M. \& other authors (2005). Tuberculosis due to resistant Haarlem strain, Tunisia. Emerg Infect Dis 11, 957-961.

McDonough, K. A. \& Kress, Y. (1995). Cytotoxicity for lung epithelial cells is a virulence-associated phenotype of Mycobacterium tuberculosis. Infect Immun 63, 4802-4811.

Nguyen, L. \& Pieters, J. (2005). The Trojan horse: survival tactics of pathogenic mycobacteria in macrophage. Trends Cell Biol 15, 269276.

Nicol, M. P., Sola, C., February, B., Rastogi, N., Steyn, L. \& Wilkinson, R. J. (2005). Distribution of strain families of Mycobacterium tuberculosis causing pulmonary and extrapulmonary disease in hospitalized children in Cape Town, South Africa. J Clin Microbiol 43, 5779-5781.

Nouvel, L. X., Kassa-Kelembho, E., Vultos, T. D., Zandanga, G., Rauzier, J., Lafoz, C., Martin, C., Blazquez, J., Talarmin, A. \& Gicquel, B. (2006). Multidrug-resistant Mycobacterium tuberculosis, Bangui, Central African Republic. Emerg Infect Dis 12, 1454-1456.

Pessolani, M. C. V., Marques, M. A. M., Reddy, V. M., Locht, C. \& Menozzi, F. D. (2003). Systemic dissemination in tuberculosis and leprosy: do mycobacterial adhesins play a role? Microbes Infect 5, 677684.

Pillay, M. \& Sturm, A. W. (2007). Evolution of the extensively drugresistant F15/LAM4/KZN strain of Mycobacterium tuberculosis in KwaZulu-Natal, South Africa. Clin Infect Dis 45, 1409-1414.

Reddy, V. M. \& Hayworth, D. A. (2002). Interaction of Mycobacterium tuberculosis with human respiratory epithelial cells (Hep-2). Tuberculosis (Edinb) 82, 31-36.

Schluger, N. W. \& Rom, W. N. (1998). The host immune response to tuberculosis. Am J Respir Crit Care Med 157, 679-691.

Small, P. M. \& Fujiwara, P. I. (2001). Management of tuberculosis in the United States. N Engl J Med 345, 189-200.

Sola, C., Filliol, I., Gutierrez, M. C., Mokrousov, I., Vincent, V. \& Rastogi, N. (2001). Spoligotype database of Mycobacterium tuberculosis: biogeographic distribution of shared types and epidemiologic and phylogenetic perspectives. Emerg Infect Dis 7, 390-396.

Sreevatsan, S., Pan, X., Stockbauer, K. E., Connell, N. D., Kreiswirth, B. N., Whittam, T. S. \& Musser, J. M. (1997). Restricted structural gene polymorphism in the Mycobacterium tuberculosis complex indicates 
evolutionarily recent global dissemination. Proc Natl Acad Sci U S A 94, 9869-9874.

Stokes, R. W., Norris-Jones, R., Brooks, D. E., Beveridge, T. J., Doxsee, D. \& Thorson, L. M. (2004). The glycan-rich outer layer of the cell wall of Mycobacterium tuberculosis acts as an antiphagocytic capsule limiting the association of the bacterium with macrophages. Infect Immun 72, 5676-5686.

Streicher, E. M., Warren, R. M., Kewley, C., Simpson, J., Rastogi, N., Sola, C., Van der Spuy, G. D., Van Helden, P. D. \& Victor, T. C. (2004). Genotypic and phenotypic characterization of drug-resistant Mycobacterium tuberculosis isolates from rural districts of the Western Cape province of South Africa. J Clin Microbiol 42, 891-894.

Valway, S. E., Sanchez, M. P. C., Shinnick, T. F., Orme, I., Agerton, T., Hoy, D., Jones, J. S., Westmoreland, H. \& Onorato, I. M. (1998). An outbreak involving extensive transmission of a virulent strain of Mycobacterium tuberculosis. N Engl J Med 338, 633-640.

Van Embden, J. D., Cave, M. D., Crawford, J. T., Dale, J. W., Eisenach, K. D., Gicquel, B., Hermans, P., Martin, C., McAdam, R. \& other authors (1993). Strain identification of Mycobacterium tuberculosis by
DNA fingerprinting: recommendations for a standardized methodology. J Clin Microbiol 31, 406-409.

Van Soolingen, D., Borgdorff, M. W., De Haas, P. E. W., Sebek, M. M. G. G., Veen, J., Dessens, M., Kremer, K. \& Van Embden, J. D. A. (1999). Molecular epidemiology of tuberculosis in the Netherlands: a nationwide study from 1993 through 1997. J Infect Dis 180, 726-736.

Velasco-Velazquez, M. A., Barrera, D., Gonzalez-Arenas, A., Rosales, C. \& Agramonte-Hevia, J. (2003). MacrophageMycobacterium tuberculosis interactions: role of complement receptor 3. Microb Pathog 35, 125-131.

Weis, S. E., Pogoda, J. M., Yang, Z., Cave, M. D., Wallace, C., Kelley, M. \& Barnes, P. F. (2002). Transmission dynamics of tuberculosis in Tarrant County, Texas. Am J Respir Crit Care Med 166, 36-42.

WHO (2009). WHO Global Report: South Africa. Available at http:// www.who.int/tb/publications/global_report/2009/pdf/zaf.pdf

Xue, L. J., Cao, M. M., Luan, J., Ren, H., Pan, X., Cao, J. \& Qi, Z. T. (2007). Mammalian cell entry protein of Mycobacterium tuberculosis induces the proinflammatory response in RAW 264.7 murine macrophage-like cells. Tuberculosis (Edinb) 87, 185-192. 